\title{
Macular Pigment Optical Density Alteration as an Indicator of Diabetic Macular Edema Development
}

\author{
DOI: $10.17691 / \mathrm{stm} 2015.7 .3 .10$
}

Received April 10, 2015

M.M. Bikbov, MD, DSc, Professor, Director;

R.M. Zainullin, Researcher, Department of Vitreoretinal and Laser Surgery;

R.R. Faizrakhmanov, MD, PhD, Senior Researcher, Head of the Department of Vitreoretinal and Laser Surgery

Ufa Scientific Research Institute of Eye Diseases, Academy of Sciences of the Republic of Bashkortostan, 90 Pushkin St., Ufa, the Republic of Bashkortostan, 450008, Russian Federation

The aim of the investigation was to reveal the peculiarities of macular pigment optical density (MPOD) alteration in diabetic macular edema.

Materials and Methods. A total of 52 patients aged 55 to 71 years (mean, $63.0 \pm 5.2$ years) were studied. The patients suffering from diabetes mellitus type 2 with diabetic macular edema (28 subjects, 30 eyes) were included in group 1 (main group). Group 2 (control group) included 24 patients (35 eyes) who did not suffer from any ophthalmic diseases and diabetes. All subjects underwent standard ophthalmic examination and fundus photographing followed with MPOD measurement using reflectometry method with non-mydreatic fundus camera VISUCAM $500^{\circledR}$ (Carl Zeiss Meditec AG, Germany).

Results. $78 \%$ of 28 patients from group 1 showed decline in all MPOD measurements as compared to control group. In particular, their mean MPOD was estimated as $0.10 \pm 0.01$ standard units of optical density $(p<0.05)$, while in the control group the same index was $0.25 \pm 0.01$ standard units of optical density $(p<0.05)$. The most significant MPOD reduction was observed in the projection of the retina edema area.

Conclusion. In diabetic macular edema, sharp decline in MPOD indices occurs. The correlation between quantitative MPOD indices and the size of the edema area has been revealed.

Key words: diabetic macular edema; macular pigment; macular pigment optical density.

Macular pigments play the role of antioxidants fighting oxidative photodamage of pigment epithelium cells and photoreceptors, as well as being effective short-wavelength light filters. In humans, macular pigments are concentrated in the outer plexiform layer of the fovea, in the stratum neurofibrarum (Henle's fiber layer), and in the outer segment membranes of photoreceptors as well [1]. Macular pigment optical density (MPOD) measurement shows the extent of protective substances preservation in relation to pathogenic factors causing macular area damage development and characterizes the condition of outer retinal layers [2, 3]. Macular pigment concentration affects directly the retinal light sensitivity, therefore regular and objective MPOD measuring proves to be rational in case of pathology of the central part of the retina $[4,5]$. Diabetic macular edema (DME) being one of the most significant signs of diabetes mellitus leads to irreversible vision loss and disability of the working-age patients [6]. However, the macular pigment condition in diabetic macular edema and their correlation have not been fully explored.

The aim of the investigation was to reveal the peculiarities of macular pigment optical density alteration in diabetic macular edema.

Materials and Methods. A total of 52 patients aged 55-71 years (mean, 63.0 \pm 5.2 years) were studied; there were $48 \%$ of men ( 25 subjects); and $52 \%$ of women ( 27 subjects). The patients under study were divided in two groups. The patients suffering from diabetes mellitus type 2 with DME and diabetic retinopathy were included in group 1 (main group), 28 subjects (30 eyes), their average diabetes duration was $10.3 \pm 3.7$ years. Group 2 (control group) included 24 patients (35 eyes) who suffered from neither ophthalmic diseases, except for presbyopia, nor diabetes.

Exclusion criterion for the study was the presence of concomitant diseases of the retina, in particular, proliferative diabetic retinopathy and vitreomacular traction syndrome. The subjects did not take medicine containing oxy-carotenoids, did not keep to a high-lutein diet.

The study was performed adhering to the tenets of the Declaration of Helsinki (adopted in June 1964 (Helsinki, Finland) and revised in October 2000 (Edinburgh, Scotland)) and approved by the local ethics committee. All subjects gave informed consent to participate in the study.

All subjects underwent standard ophthalmic examination involving visometry and ophthalmic biomicroscopy with the aid of 78D aspheric lens (Russia). Fundus photography with MPOD measurement was performed by reflectometry method with non-mydreatic fundus camera VISUCAM $500^{\circledR}$ (Carl Zeiss Meditec AG, Germany). Macular pigment volume, distribution area, maximum and mean values of

For contacts: Faizrakhmanov Rinat Rustamovich, e-mail: Rinatrf@gmail.com 
macular pigment concentration were used to estimate MPOD.

Statistical processing of the results was performed by using the methods of descriptive statistics, univariate ANOVA test and a posteriori Duncan's test for multiple comparisons. The variations were considered significant, when $p<0.05$. The descriptive statistics results are given as $M \pm m$, where $M$ is mean value, $m$ is standard deviation. The critical level of statistical significance when testing a zero hypothesis was set to be 0.05 .

Results and Discussion. According to ophthalmoscopy findings, the patients from group 1 showed the changes

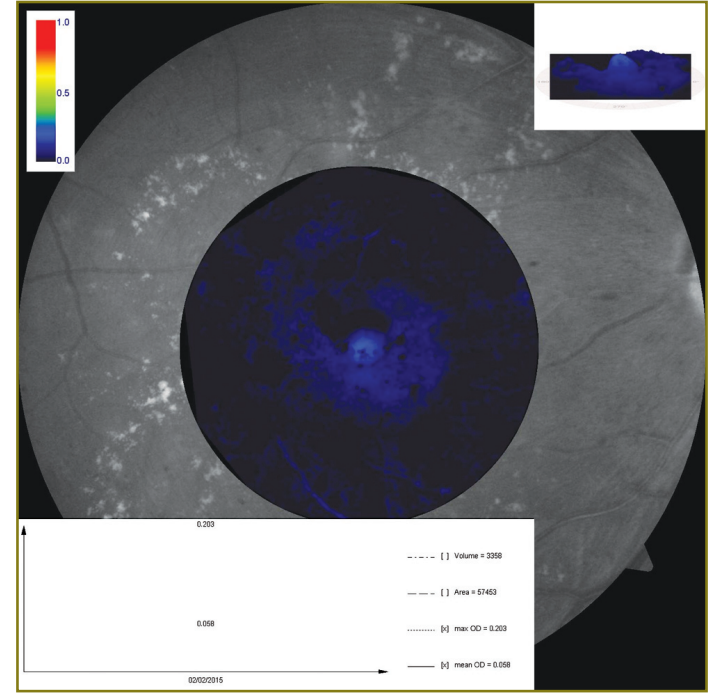

a

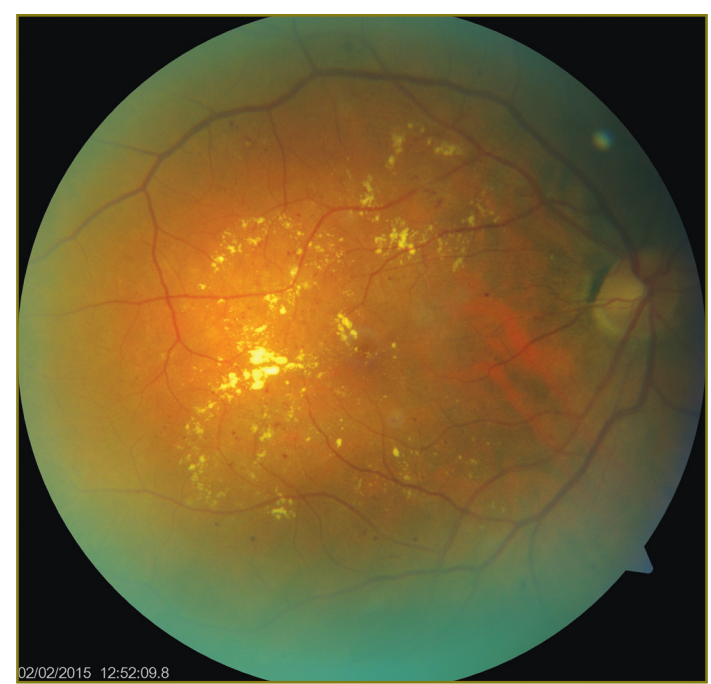

C

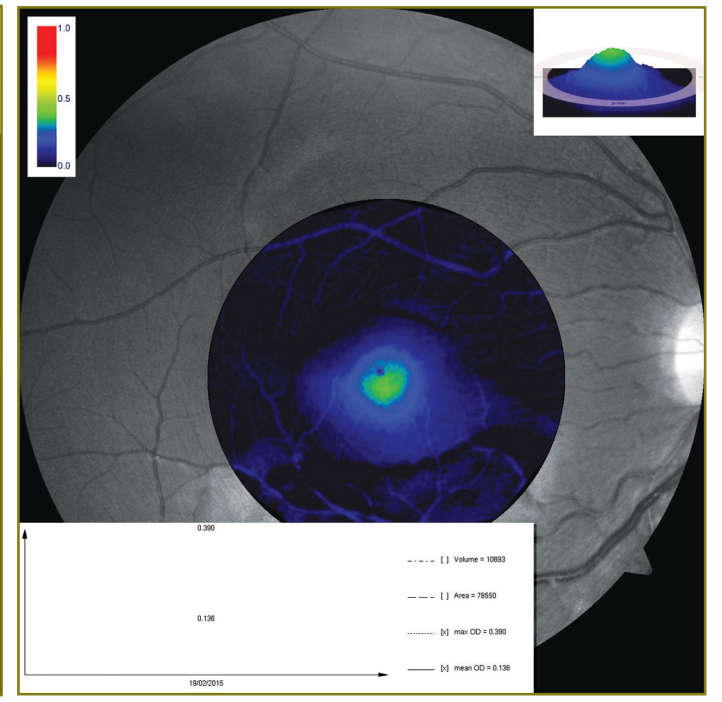

b

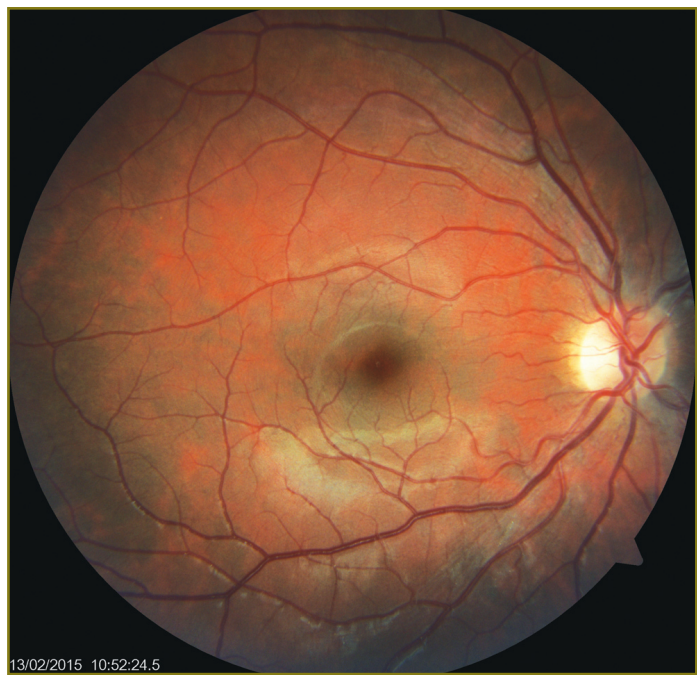

d

The fundus images and graphic cartogram analysis of macular pigment optical density in a patient with diabetic retinopathy (a), (b) and in a patient without diabetes mellitus (c), (d)

\section{Mean macular pigment optical density values in patients of compared groups}

\begin{tabular}{lccccc}
\hline \multicolumn{1}{c}{ Groups } & $\begin{array}{c}\text { Maximum macular pigment } \\
\text { optical density value } \\
\text { (standard units } \\
\text { of optical density) }\end{array}$ & $\begin{array}{c}\text { Mean macular pigment } \\
\text { optical density value (standard } \\
\text { units of optical density) }\end{array}$ & $\begin{array}{c}\text { Macular pigment } \\
\text { distribution area (pixels) }\end{array}$ & $\begin{array}{c}\text { Macular pigment volume } \\
\text { (standard units of optical } \\
\text { density } \times \text { pixels) }\end{array}$ \\
\hline With diabetic retinopathy & $0.32 \pm 0.01^{*}$ & $0.10 \pm 0.01^{*}$ & $54484.92 \pm 14769.36$ & $4106.83 \pm 1080.58^{*}$ \\
Without diabetes mellitus & $0.69 \pm 0.02$ & $0.25 \pm 0.01$ & $63651.0 \pm 15234.23$ & $15702.0 \pm 3043.23$ \\
\hline
\end{tabular}

* Statistically significant differences in values as compared to control group $(p<0.05)$. 
characteristic of diabetic retinopathy, such as microaneurysms, preretinal hemorrhage, hard and/or soft exudates; retinal edema; intraretinal microvascular abnormalities (marked venous dilation, their size irregularity, convolution, vascular slings). According to Kohner and Porta classification (1991), this group of patients suffered from non-proliferative or pre-proliferative stage of retinopathy.

MPOD measurement results were analyzed using graphic cartograms in the form of spatial distribution profiles and comparing the measured values: the mean and maximum optical density, macular pigment volume and distribution area (See the Figure).

When analyzing the obtained results significant decrease in all MPOD indices was found in $78 \%$ of patients from group 1 as compared to control group (See the Table).

The obtained results have shown major retinal structure impairments and MPOD distribution derating in DME patients. The most significant MPOD reduction has been observed in the projection of the macular edema area. Considering the correlation between MPOD and the layer of photoreceptors, as well as the decline in macular pigment density indices in the edema area, according to the findings of this study, the layer of photoreceptors can presumably be involved in a pathological process. Whether photoreceptors damage is a secondary event in diabetic macular edema requires further detailed investigation using additional research methods.

Thus, the study of MPOD indices in patients with diabetes mellitus should be performed as soon as possible for earlier detection of diabetic retinal alterations. Hereafter, the alterations found in the course of observation can be used as an indicator of the process progressing and for the disease prognosis. MPOD study can be a form of screening DME patients, which, in terms of results, is comparable to identifying visual fields or measuring the thickness of the nerve fiber layer in glaucoma.

Conclusion. In diabetic macular edema, sharp decline in macular pigment optical density indices occurs. The correlation between quantitative macular pigment optical density indices and the size of the edema area has been revealed. Macular pigment optical density measurement can serve as an additional informative procedure for individual monitoring of patients with diabetic macular edema.

Study Funding and Conflicts of Interest. This study was not supported by any financial sources, and there is no conflict of interests associated with the research.

\section{References}

1. Chucair A.J., Rotstein N.P., SanGiovanni J.P., During A., Chew E.Y., Politi L.E. Lutein and zeaxanthin protect photoreceptors from apoptosis induced by oxidative stress: relation with docosahexaenoic acid. Invest Ophthalmol Vis Sci 2007; 48(11): 5168-5177, http://dx.doi.org/10.1167/iovs. 07-0037.

2. Raman R., Rajan R., Biswas S., Vaitheeswaran K., Sharma T. Macular pigment optical density in a South Indian population. Invest Ophthalmol Vis Sci 2011; 52(11): 7910-7916, http://dx.doi.org/10.1167/iovs.11-7636.

3. Kaya S., Weigert G., Pemp B., Sacu S., Werkmeister R.M., Dragostinoff N., Garhöfer G., SchmidtErfurth U., Schmetterer L. Comparison of macular pigment in patients with age-related macular degeneration and healthy control subjects - a study using spectral fundus reflectance. Acta Ophthalmol 2012; 90(5): e399-e403, http://dx.doi. org/10.1111/j.1755-3768.2012.02423.x.

4. Rothenbuehler S.P., Wolf-Schnurrbusch U.E.K., Wolf S. Macular pigment density at the site of altered fundus autofluorescence. Graefes Arch Clin Exp Ophthalmol 2011; 249(4): 499-504, http://dx.doi.org/10.1007/s00417-010-1528-1.

5. lannaccone A., Mura M., Gallaher K.T., Johnson E.J., Todd W.A., Kenyon E., Harris T.L., Satterfield S., Johnson K.C., Kritchevsky S.B. Macular pigment optical density in the elderly: findings in a large biracial Midsouth population sample. Invest Ophthalmol Vis Sci 2007; 48(4): 1458-1465, http://dx.doi. org/10.1167/iovs.06-0438.

6. Astakhov Y.S., Shadrichev F.E., Krasavina M.G., Grigorieva N.N. Modern approaches to diabetic macular edema treatment. Oftal'mologicheskie vedomosti 2009; 2(4): 59-69. 